\title{
Intracranial Electroencephalographic Monitoring: From Subdural to Depth Electrodes
}

\author{
Holger Joswig, David A. Steven, Andrew G. Parrent, Keith W. MacDougall, \\ Seyed M. Mirsattari, Richard S. McLachlan, David C. Diosy, Jorge G. Burneo
}

\begin{abstract}
At the London Health Sciences Centre Epilepsy Program, stereotactically implanted depth electrodes have largely replaced subdural electrodes in the presurgical investigation of patients with drug-resistant epilepsy over the past 4 years. The rationale for this paradigm shift was more experience with, and improved surgical techniques for, stereoelectroencephalography, a possible lower-risk profile for depth electrodes, better patient tolerability, shorter operative time, as well as increased recognition of potential surgical targets that are not accessible to subdural electrodes.
\end{abstract}

RÉSUMÉ: Assurer un meilleur suivi de l'activité intracrânienne au moyen de l'électroencéphalographie: passer des électrodes sous-durales aux électrodes implantées en profondeur. Au cours des quatre dernières années, au Centre des sciences de la santé de London (Ontario), établissement offrant un programme de traitement de l'épilepsie, des électrodes implantées en profondeur de manière stéréotaxique ont en grande partie remplacé les électrodes sous-durales dans le cas d'examens pré-chirurgicaux menés auprès de patients atteints d'épilepsie réfractaire aux médicaments. Ce changement de paradigme tient à plusieurs facteurs : une plus grande expérience avec les techniques chirurgicales liées à la stéréo-électroencéphalographie, ces dernières ayant été améliorées ; un niveau de risque possiblement moins élevé dans le cas des électrodes en profondeur ; une meilleure tolérance chez les patients ; des temps opératoires plus courts de même que l'identification accrue de cibles chirurgicales potentielles auxquelles les électrodes sous-durales n'ont pas accès.

Keywords: Depth Electrodes, Epilepsy Surgery, Stereoelectroencephalography, Subdural Electrodes

doi:10.1017/cjn.2018.4

Can J Neurol Sci. 2018; 45: 336-338

As one of Canada's high-volume adult epilepsy surgery centers, ${ }^{1}$ a large number of our patients at London Health Sciences Centre with drug-resistant epilepsy are subjected to intracranial electroencephalographic monitoring. ${ }^{2}$ The first subdural electrodes (SE) were implanted in London in 1979 by John Girvin, who had trained at the Montreal Neurological Institute, and soon became our routinely employed invasive diagnostic standard for presurgical investigation ${ }^{1}$ when surface electroencephalography could not delineate the seizure onset zone sufficiently. ${ }^{2}$ With our SE implantation technique, ${ }^{3}$ complication rates were low; ${ }^{4,5} 75 \%$ of all patients investigated with SE proceded to resective surgery for epilepsy, which resulted in seizure-freedom at 1 year (Engel I) in $47 \%$ of the cases. ${ }^{4}$

Subdural electrodes for intracranial electroencephalographic monitoring were first introduced by Herbert Jasper in the 1950s. In parallel, stereoelectroencephalography (SEEG) was pioneered by Talairach and Bancaud at Sainte Anne Hospital, Paris. ${ }^{2}$ Depth electrode (DE) for SEEG were also used at the Montreal Neurological Institute in the 1970s, and, in fact, further technically refined by the introduction of digital subtraction angiography in the 1980s and double-dose gadolinium magnetic resonance imaging in the 1990s. ${ }^{6}$

A paradigm shift toward SEEG has taken place at our institution since 2013, and DE have almost entirely replaced SE (Figure 1). Given the lack of high-quality studies that directly compare the superiority of one technique over the other, the use of SE versus SEEG remains a pivotal discussion and must be viewed as equipoise; the choice between the two techniques is dependent on the question of the electroencephalographic investigation ${ }^{7}$ and is a matter of institutional preference.

Although "open" combined SE and DE variants via a craniotomy were not uncommon, our first "stand-alone" stereotactic DE implantation for SEEG at our institution did not take place until 2003 (Figure 1); however, this case was challenged by the lack of technical refinements such as anchor bolts, for example, and SEEG was not resumed until a decade later. In 2013 and 2014, SEEG was performed for $28 \%$ of all our invasive electroencephalographic monitoring cases, and this percentage increased to $95 \%$ in the past 2 years (Figure 1). The considerations presented in this manuscript factored into our adopted change in practice. Our observation of (clinically silent) magnetic resonance

From the Epilepsy Program, Department of Clinical Neurological Sciences, Schulich School of Medicine and Dentistry, Western University, London, Ontario, Canada (HJ, DAS, AGP, KWM, SMM, RSM, DCD, JGB).

Received August 21, 2017. Final Revisions Submitted November 9, 2017. Date of AcCePtance November 10, 2017.

Correspondence to: Jorge G. Burneo, Epilepsy Program, Department of Clinical Neurological Sciences, Schulich School of Medicine and Dentistry, Western University, London, ON, Canada. Email: jburneo2@uwo.ca 


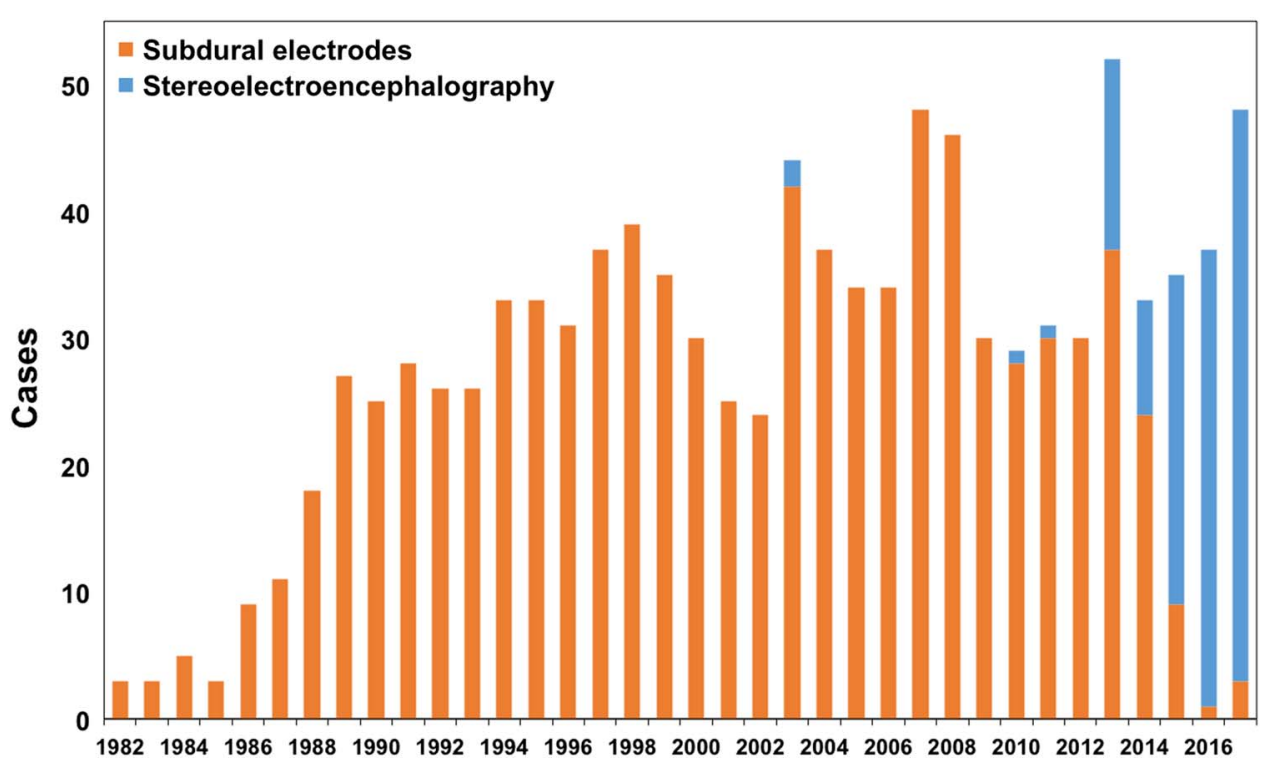

Figure 1: Absolute case numbers of subdural strip/grid electrodes and depth electrodes for stereoelectroencephalography over time at the London Health Sciences Centre Epilepsy Program in London Ontario, Canada. Over the past 3 years, the latter have evolved into the principle means of intracranial electroencephalographic monitoring in the presurgical investigation of drug-resistant epilepsy.

imaging abnormalities after SE placement ${ }^{8}$ and expert opinions on lower complication rates ${ }^{6}$ prompted a new generation of epileptologists and epilepsy surgeons ${ }^{1}$ to give a new impetus to implementing SEEG. In the same vein, increased experience with stereotactic treatments for epilepsy ${ }^{9}$ built up our confidence, allowing us to finally overcome the learning curve of Leksell frame-based stereotactic DE implantation as it is now at our institution. ${ }^{10}$ It is our anecdotal experience that patients with DE suffer from fewer postoperative headaches and less discomfort than after SE implantation. Cerebrospinal fluid leakage is almost never encountered after SEEG. Last, mean operative time for SEEG is shorter by half an hour ( $p<0.05$; unpublished data). Over the years, we have learnt to adapt to the "three-dimensional thinking" in SEEG and to appreciate the possibility of investigating deeper structures, such as the insula or deeply situated heterotopic gray matter. In fact, as previously stated, ${ }^{2}$ as DE, by virtue of their longitudinal recording area, cover both deep and superficial cortical structures, "DE" is a misnomer. Our previous anatomical thinking as subdural implanters developed into a more network-based understanding of epilepsy that emphasizes semiology for planning "punctuate" DE for SEEG, which, in fact, samples less brain. On the basis of these principles and with more experience with DE extraoperative cortical stimulation, we no longer regard SE "more useful than DE to identify areas of eloquent cortex". ${ }^{2}$ Yet, we still make use-and will make future use - of SE and grids in selected cases where high-resolution extraoperative cortical simulation is warranted, as well as in very young patients or in those with contraindications to undergo magnetic resonance imaging for presurgical planning. Specific indications, strengths, and limitations of both techniques, as well as a flow-chart protocol are well summarized in a recent consensus-based expert recommendation. ${ }^{7}$

With the advent of new imaging technologies, the presurgical invasive diagnostic armamentarium continues to grow. ${ }^{7}$ A need for a considerate selection of old and new invasive intracranial monitoring techniques or a combination of both ${ }^{7}$ to accurately localize the seizure focus remains. ${ }^{2}$

\section{DisCLOSURES}

HJ reports personal fees from UCB Canada, non-financial support from Fujirebio Europe N.V. (Ghent, Belgium), outside the submitted work; DAS, KWM, RSM, and DCD have nothing to disclose; AGP reports personal fees from Medtronic, outside the submitted work; SMS reports personal fees from UCB Pharma, personal fees from Eisai Limited, and personal fees from Sunovion Pharmaceuticals Canada, Inc., outside the submitted work; JGB reports grants and personal fees from UCB Pharma, personal fees from Eisai Limited, grants from Epilepsy Canada, and grants from Ontario Brain Institute, outside the submitted work.

\section{Statement OF Authorship}

HJ: study conceptualization, data collection, manuscript drafting/finalization, literature research, and creation/edit of Figure 1. DAS, AGP, KWM, SMM, RSM, and DCD: data collection and manuscript review. JGB: study conceptualization and supervision, data collection, creation/edit of Figure 1, and manuscript review.

\section{REFERENCES}

1. Blume WT, Girvin JP. A history of the epilepsy programme at University Hospital (LHSC) \& Western University, London, Ontario Canada 1975-2012. Can J Neurol Sci. 2012;39(Suppl 6):S2-6.

2. Dubeau F, McLachlan RS. Invasive electrographic recording techniques in temporal lobe epilepsy. Can J Neurol Sci. 2000; 27(Suppl 1):S29-34; discussion S50-2.

3. Steven DA, Andrade-Souza YM, Burneo JG, McLachlan RS, Parrent AG. Insertion of subdural strip electrodes for the investigation of temporal lobe epilepsy. Technical note. J Neurosurg. 2007; 106(6):1102-6. 
4. MacDougall KW, Burneo JG, McLachlan RS, Steven DA. Outcome of epilepsy surgery in patients investigated with subdural electrodes. Epilepsy Res. 2009;85(2-3):235-42.

5. Burneo JG, Steven DA, McLachlan RS, Parrent AG. Morbidity associated with the use of intracranial electrodes for epilepsy surgery. Can J Neurol Sci. 2006;33(2):223-7.

6. Cardinale F, Casaceli G, Raneri F, Miller J, Lo Russo G. Implantation of Stereoelectroencephalography electrodes: a systematic review. J Clin Neurophysiol. 2016;33(6):490-502.

7. Jayakar P, Gotman J, Harvey AS, et al. Diagnostic utility of invasive EEG for epilepsy surgery: indications, modalities, and techniques. Epilepsia. 2016;57(11):1735-47.
8. Al-Otaibi FA, Alabousi A, Burneo JG, Lee DH, Parrent AG, Steven DA. Clinically silent magnetic resonance imaging findings after subdural strip electrode implantation. J Neurosurg. 2010; 112(2):461-6.

9. Parrent AG, Blume WT. Stereotactic amygdalohippocampotomy for the treatment of medial temporal lobe epilepsy. Epilepsia. 1999:40(10):1408-16.

10. Joswig H, Benson CM, Parrent AG, MacDougall KW, Steven DA. Operative nuances of stereotactic Leksell frame-based depth electrode implantation. Oper Neurosurg (Hagerstown) 2017 Dec 7. doi:10.1093/ons/opx245 [Epub ahead of print]. 